\title{
Income, occupational position, qualification and health inequalities - competing risks? (Comparing indicators of social status)
}

\author{
Siegfried Geyer, Richard Peter
}

\begin{abstract}
Study objective-The debate on health inequalities has shifted from the consequences of occupational position, as expressed in the Registrar General's classification, to consequences of material living conditions. This change in interest occurred without comparative analyses of different sources of health inequalities. Thus this study investigated the relative contribution of "material resources" (income), "qualification" and "occupational position" for explaining social differentials in mortality.

Design and setting-Analyses were performed with records from a statutory health insurance in West Germany. The analyses were performed with data of 84814 employed men and women between 25 and 65 years of age who were insured between 1987 and 1995 for at least 150 days.
\end{abstract}

Results-The three indicators were statistically associated, but not strong enough to warrant the conclusion that they share the same empirical content. The relative risk (hazard rate) for income by controlling for occupational position and gender for the highest as compared with the lowest category was 1.99 (95\% CI 1.66, 2.39). The corresponding relative risk for income by controlling for qualification and gender was $2.03(95 \%$ CI $1.68,2.46)$. In both multivariate analyses, the effects of occupational position and qualification were no longer interpretable because of large confidence intervals. In sum, income related relative mortality risks were the comparably highest, while qualification and occupational position were no longer substantial.

Conclusions-The results emphasise the present discussion on the consequences of material living conditions. Income on the one hand and qualification and occupational position on the other are largely independent. Mortality related effects of income override those of the other socioeconomic status indicators. However, seen in a time perspective, qualification may still have a placement function at least for the first occupational position.

(F Epidemiol Community Health 2000;54:299-305)

In recent years the main interest of the scientific discussion on social inequalities in health has changed. A review from the beginning of the 1990s documents the main research interest in health related effects of occupational position, ${ }^{1}$ but in the recent literature the emphasis is laid on the health consequences of material living conditions..$^{2-6}$ The theoretical concept behind is deprivation, assuming that material conditions may influence a wide variety of health related aspects of life including opportunities for a healthy lifestyle and health promoting behaviours, or the satisfaction of basic needs. The scientific discussion is centred around absolute ${ }^{7}$ or relative deprivation, while for Western European countries relative deprivation is assumed to be relevant. ${ }^{578}$

The main indicator of material conditions is income, assessed on an aggregate level ${ }^{39}$ or on the individual level. ${ }^{6}{ }^{10}$ Other options are occupational position, ${ }^{11-16}$ formal education attained at school, vocational training, ${ }^{217} 18$ or a combined index. ${ }^{19}{ }^{20}$ Either indicator has been demonstrated to be associated with increased risks for health impairments and mortality. ${ }^{11}{ }^{20-22}$ The above mentioned shift of the inequality debate to material conditions was not triggered by empirically based insights that material conditions had more powerful effects on health related outcomes than qualification or occupational position. In some studies a comparative perspective was adopted. In the Health and Lifestyle Survey, Blaxter ${ }^{22}$ assessed the three indicators of socioeconomic status (SES) and considered the relations with several measures of impaired health. After having compared income and social class, it was concluded that income was the most powerful predictor for measures of illness and impaired psychosocial health.

In another study the data from several cross sectional surveys were compiled. ${ }^{24}$ The association of education, income and occupation with several measures of cardiovascular risks suggested the strongest effect for income. Unfortunately, the categories of the three SES indicators had not been considered separately, and the statistical measures applied were not quite appropriate.

In a recent study education, occupation and a proxy measure of household income were considered with respect to the presence of chronic conditions and subjective health. ${ }^{25}$ The bivariate analyses revealed the well known social gradient to the disadvantage of the lowest SES groups. The multivariate analyses did not demonstrate monotonous increases of health impairments with decreasing SES. Unfortunately, the confidence intervals had 
Table 1 Univariate distributions of qualification and occupational position

\begin{tabular}{|c|c|c|c|}
\hline \multicolumn{2}{|l|}{ Qualification } & \multicolumn{2}{|l|}{ Occupational position } \\
\hline Max 10 years of school without apprenticeship & $41259(33.6 \%)$ & Unskilled/semi-skilled & $61896(48.4 \%)$ \\
\hline 9 or 10 years of school and apprenticeship & $69727(56.8 \%)$ & Skilled manuals & $30469(23.8 \%)$ \\
\hline 13 years of school with or without apprenticeship & $4321(9.6)$ & Skilled non-manuals & $26342(20.6 \%)$ \\
\hline University education & $7461(6.1)$ & Intermediates/professionals & $9354(7.3 \%)$ \\
\hline Total number with valid values & $122776(100 \%)$ & $\begin{array}{l}\text { Total number with valid } \\
\text { values }\end{array}$ & $128151(100 \%)$ \\
\hline Missing cases & $24488(16.6 \%)^{\star}$ & Missing cases & $6777(4.6 \%)^{\star}$ \\
\hline
\end{tabular}

*Percentages for missing cases refer to the total study population of 147264 subjects.

not been reported (page 596), thus there is some ambiguity in the interpretation of the results. Such comparisons are however important as the three indicators refer to different facets of social stratification:

Income determines limiting material conditions nesessary to satisfy the basic needs of life and above. It also provides resources for mastering demanding situations by seeking professional assistance and by determining opportunities for healthy lifestyles. ${ }^{7}$

Education is an indicator for knowledge, for the ability to use it more or less effective in terms of mental flexibility and to cope successfully with demanding or potentially stressful situations. ${ }^{26} 27$

Occupational status is indicative of health related concomitants of the job like variations of control over the workplace, ${ }^{262829}$ differing reward structures ${ }^{30}$ or toxic hazards.

Thus, improved risk predictions can be expected if more than one indicator of SES is used. Instead, the three indicators should be included and compared with respect to their relative contribution to explaining mortality risks. Before doing so, a precondition has to be met. It can be assumed that the indicators are not independent from each other. In the case of high intercorrelations it would be unimportant which one is chosen as social status measure, and the present discussion on relative deprivation would repeat a previous one performed under a different heading.

The foregoing considerations lead to two research problems:

(1) Given that occupational position, qualification and income refer to different aspects, they will have to be distinguished also on the empirical level-that is, their intercorrelations should not be too high. Thus their empirical overlaps have to be examined.

(2) The contribution of income has to be compared with occupational position and qualification with respect to mortality risks.

This paper aims to contribute to the ongoing discussion on social differentials in health by evaluating the relative importance of the main social status indicators. The comparative studies above were concerned with subjective health, morbidity and indicators of cardiovascular risks. In the following analyses we will consider all cause mortality as outcome. A large data set will be used to avoid unstable estimates that may occur if the study population is broken down into many categories.

\section{Method}

STUDY POPULATION

The data for this study were provided from a German statutory health insurance. They were collected for accounting purposes between 1987 and 1995; the study population consists of 147264 employed men and women between 25 and 65 years of age insured for at least 150 days. Because of missing information on at least one indicator, the eligible number was reduced to 84814 , with 57078 (68.9\%) being men, and 27736 (31.1\%) women.

Every SES indicator contributes to the amount of missing values (table 1 ), but the majority is attributable to income with 43638 cases without information; the reasons will be explained below. In table 1 income is not represented as the eligible number was divided into income quintiles. Table 2 gives information on the distribution of gender and age for people with and without missing values.

The distribution of age was not affected from the loss of cases without SES information, missings on income leads to a smaller proportion of men in the eligible study population. The data base contains insured with full time and part time employment; actually it would be appropriate to treat them separately, but the available information did not permit to differentiate between them. For the whole study population, the person years add up to a total of 2457356 with a mean (SD) observation period of 5.6 (3.8) years. The respective figure for the eligible population is 1360262 person years and a mean (SD) observation period of 6.2 (3.6) years. Thus, the missings rather concerned people with shorter insurance periods.

During the study period 1347 deaths were recorded, but the distribution is biased as women account for only $17 \%$ of them. The clientele of local health insurances does not correspond to the status distribution of the

Table 2 Distributions of sex and age for the independent variables

\begin{tabular}{llllllll}
\hline & $\begin{array}{l}\text { Whole } \\
\text { population }\end{array}$ & $\begin{array}{l}\text { Income, valid } \\
\text { values }\end{array}$ & $\begin{array}{l}\text { Income } \\
\text { missing }\end{array}$ & $\begin{array}{l}\text { Qualification } \\
\text { valid values }\end{array}$ & $\begin{array}{l}\text { Qualification } \\
\text { missing }\end{array}$ & $\begin{array}{l}\text { Occupational } \\
\text { position valid } \\
\text { values }\end{array}$ & $\begin{array}{l}\text { Occupational } \\
\text { position missing }\end{array}$ \\
\hline Sex, male & $72.4 \%$ & $69.8 \%$ & $78.7 \%$ & $72.3 \%$ & $72.7 \%$ & $72.2 \%$ & $76.1 \%$ \\
Sex, female & $27.6 \%$ & $30.2 \%$ & $21.3 \%$ & $27.7 \%$ & $27.3 \%$ & $27.8 \%$ & $23.9 \%$ \\
Age $(\mathrm{y})^{\star}$ & $42.5(11.8)$ & $42.5(11.8)$ & $42.5(11.8)$ & $42.5(11.8)$ & $42.5(11.8)$ & $42.5(11.8)$ & $42.5(11.8)$ \\
\hline
\end{tabular}

^For age, means (SD) are presented. 
German population. Because of peculiarities of the German health insurance system, lower socioeconomic groups are overrepresented, while relatively few persons of higher occupational status are included.

The catchment area is an urban or urbanised area west of Düsseldorf, the district of Mettmann. The population under study was employed either in the production industry or in the service sector, they were employed until the age of death or until the age of 65 . Those who were jobless or retired before the end of 1995 were assigned their earlier occupational status position. People who lost their job may cause some ambiguities. In case of retiring prematurely, they will have continuing health insurance. In case of being on unemployment benefits, the coverage will be retained for two years, in many cases this took place for more than five years. Subsequently they will be on welfare aid, then only some of them will continue to be insured. No farmers $(4.1 \%$ of the economically active population in Germany $1988,3.0 \%$ in 1996$)^{3132}$ are included as they have their own insurance.

Occupational group membership was determined using an official three digit classification issued by the German Labour Authority (Bundesanstalt für Arbeit (BfA))..$^{33}$ These categories were collapsed into five groups: "unskilled and semi-skilled positions", "skilled manuals", "skilled non-manuals", "intermediates" and "professionals". Because of the small number of professionals, intermediates and professionals had to be counted together.

When combining occupations to groups, their qualification levels as published by the German Institut für Arbeitsmarkt-und Berufsforschung (Institute of Labour Market and Occupation Research) were taken into account. ${ }^{34}$ If the qualification structure of a given occupation is homogeneous, this will not cause serious problems, in case of being rather heterogeneous, the assignment into one of the five categories was performed according to a "typical" case holding this occupation. In Germany information on occupational changes is routinely transferred from the employer to the health insurance. In the analyses below the highest level attained was used.

Qualification was determined according to a four categorial system based on a classification issued also by the German Labour Authority. The insured were classified by "nine or ten years of school or less without vocational training", "nine or ten years of school and vocational training", "13 years of school without or with vocational training", and "academic training". Like occupational group membership the qualificational information is supplied by the employer, and in the analyses to follow the classification above will be used.

Income (attributable to employment) is an information transmitted from the employer to the insurance as it is the basis for calculating the insurance fees. An indirect measure for income was chosen. Not all the subjects were insured throughout the observation period. Some had long been in the insurance before electronic data storage started (1987), for some people coverage began and ended between 1987 and 1995, others entered the insurance after 1987 and had continuous coverage. The numerical amount of wages during the nine year observation period increased without a parallel rise of purchasing power necessarily having taken place, thus monthly revenues of DM 3000 in 1987 and 1995 are not comparable. This made it necessary to standardise individual incomes. If people were insured for more than one year, the amounts were converted into a one year reference period. To obtain comparability, for each person the deviation from the mean per year was calculated. The means of these deviations were computed, and served as our indicator for income. In the statistical analyses below the income continuum is transformed into categories of five percentiles.

It has already been mentioned that the largest number of missing data occurred with regard to income. Actually for all insured with an occupation, income information is available as this is the basis for the calculations of insurance premiums. Missing values were assigned if unusually high or unusually low payments were recorded. This concerned single payments, transitional periods with formal employment, but without payment, rehabilitation periods, etc. In case of constant insurance this did not cause classification problems, but if people were insured for shorter intervals, we could not compute a regular income and had to assign missing values.

\section{STATISTICAL ANALYSES}

The following analyses are based on cross tabulations for inspecting the data, on Spearman rank order correlations for associations between the indicators, and on Cox regression ${ }^{35}{ }^{36}$ to estimate relative risks in the multivariate analyses. Regression analysis using the Cox proportional hazards model is appropriate here because it takes time (in the following analyses age) into consideration. It can handle insurance periods of differing lengthsthat is, people leaving the population before the age of 65 will not lead to biased results. Cox regression depicts a time process whereas it is assumed that an event (in the present case mortality) will occur as a function of time having elapsed. Some proportion of the population will die within the observation period (here: until the age of 65), and the remaining people will survive. If covariates are introduced (in the present case indicators of socioeconomic status and gender) for every covariate it will be estimated to what extent the time process is altered - that is, whether the respective risks of death events for defined groups decrease or increase. Thus adjusting for age is not appropriate. The dependent variable is risks of mortality until the age of 65 . The statistical analyses were conducted in two steps. At first the independent effect of each SES indicator was estimated in separate regression models. Then effects of qualification with income, and occupational position with income were estimated.

The data management was performed with SPSS $6.1^{37}$ on PC, the regression models were computed with STATA $6.0 .^{38}$ 
Results

At first the distribution of the three indicators for SES are considered. According to the first research question it will be analysed to what extent they do overlap.

In terms of Spearman rank correlations, the strongest association appears between qualification and occupational position $(r=0.58)$ while the correlations between each of these and income are rather weak $(r=0.13$ and $r=0.11$, respectively). If the distributions are considered in detail, it emerges that $71.6 \%$ of the unskilled and semi-skilled do not have a qualification. Considering this relation from the other side, $86.5 \%$ of the insured without a qualification hold unskilled jobs. We find similar, but no identical results for the more privileged segment of the distribution: $37.3 \%$ of the higher positions are occupied by people with a high qualification.

Comparing positions of income and occupational status yields an interpretable, but smaller association, the rank correlation is only $r=0.11$. If the distributions are considered in detail (table 3), it turns out that this is because the extreme ends as $71 \%$ in the lowest income group hold unskilled or semi-skilled positions, but having a lower occupational status does not necessarily go together with low incomes. For the opposite part of the distributions this holds to a smaller degree as only $32.9 \%$ of the intermediates or executives receive the highest sala-

Table 3 Income by qualification

\begin{tabular}{|c|c|c|c|c|c|}
\hline $\begin{array}{l}\text { Frequencies } \\
\text { Rowv-\% } \\
\text { Column-\% }\end{array}$ & Qualification(1)* & Qualification(2)* & Qualification(3)* & Qualification(4)* & \\
\hline & 334 & 2331 & 8544 & 8422 & \\
\hline \multirow[t]{3}{*}{ Highest $20 \%$} & $1.7 \%$ & $11.9 \%$ & $43.5 \%$ & $42.9 \%$ & 19631 \\
\hline & $32.9 \%$ & $22.9 \%$ & $35.8 \%$ & $15.8 \%$ & \\
\hline & 196 & 1702 & 6613 & 10340 & \\
\hline \multirow[t]{3}{*}{ Higher $20 \%$} & $1.0 \%$ & $9.0 \%$ & $35.1 \%$ & $54.9 \%$ & 18851 \\
\hline & $19.3 \%$ & $16.7 \%$ & $27.7 \%$ & $19.4 \%$ & \\
\hline & 161 & 1656 & 4245 & 11907 & \\
\hline \multirow[t]{3}{*}{ Mean $20 \%$} & $0.9 \%$ & $9.2 \%$ & $23.6 \%$ & $66.3 \%$ & 17969 \\
\hline & $15.9 \%$ & 16.3 & $17.8 \%$ & $22.4 \%$ & \\
\hline & 128 & 1861 & 2873 & 11758 & \\
\hline \multirow[t]{3}{*}{ Lower $20 \%$} & $0.8 \%$ & $11.2 \%$ & $17.3 \%$ & $70.7 \%$ & 16620 \\
\hline & $12.6 \%$ & $18.3 \%$ & $12.0 \%$ & $22.1 \%$ & \\
\hline & 195 & 2615 & 1597 & 10792 & \\
\hline \multirow[t]{3}{*}{ Lowest $20 \%$} & $1.3 \%$ & $17.2 \%$ & $10.5 \%$ & $71.0 \%$ & 15199 \\
\hline & $19.2 \%$ & $25.7 \%$ & $6.7 \%$ & $20.3 \%$ & \\
\hline & 1014 & 10165 & 23872 & 53219 & 88270 \\
\hline
\end{tabular}

*Qualification(1): "University education" Qualification(2): "13 years of school with or without vocational training" Qualification(3): "9 or 10 years of school and apprenticeship" Qualification(4): "Max. 10 years of school without apprenticeship."

Table 4 Income by occupational position

\begin{tabular}{|c|c|c|c|c|c|}
\hline $\begin{array}{l}\text { Frequencies } \\
\text { Row-\% } \\
\text { Column-\% }\end{array}$ & $\begin{array}{l}\text { Intermediate } \\
\text { occupations and } \\
\text { professionals }\end{array}$ & $\begin{array}{l}\text { Skilled manual } \\
\text { occupations }\end{array}$ & $\begin{array}{l}\text { Skilled } \\
\text { non-manual } \\
\text { occupations }\end{array}$ & $\begin{array}{l}\text { Unskilled and } \\
\text { semi-skilled } \\
\text { occupations }\end{array}$ & \\
\hline & 422 & 2948 & 9317 & 8422 & \multirow{4}{*}{21109} \\
\hline \multirow[t]{3}{*}{ Highest $20 \%$} & $2.0 \%$ & $14.0 \%$ & $44.1 \%$ & $39.9 \%$ & \\
\hline & $31.0 \%$ & $21.4 \%$ & $30.7 \%$ & $15.8 \%$ & \\
\hline & 265 & 2254 & 7996 & 10340 & \\
\hline \multirow[t]{3}{*}{ Higher $20 \%$} & $1.3 \%$ & $10.8 \%$ & $38.3 \%$ & $49.6 \%$ & \multirow[t]{3}{*}{20855} \\
\hline & $19.4 \%$ & $16.3 \%$ & $26.3 \%$ & $19.4 \%$ & \\
\hline & 220 & 2270 & 5887 & 11907 & \\
\hline \multirow[t]{3}{*}{ Mean $20 \%$} & $1.1 \%$ & $11.2 \%$ & $29.0 \%$ & $58.7 \%$ & \multirow[t]{3}{*}{20284} \\
\hline & $16.1 \%$ & $16.5 \%$ & $19.4 \%$ & $22.4 \%$ & \\
\hline & 196 & 2747 & 4626 & 11758 & \\
\hline \multirow[t]{3}{*}{ Lower $20 \%$} & $1.0 \%$ & $14.2 \%$ & $23.9 \%$ & $60.8 \%$ & \multirow[t]{3}{*}{19327} \\
\hline & $14.4 \%$ & $19.9 \%$ & $15.2 \%$ & $22.1 \%$ & \\
\hline & 260 & 3572 & 2531 & 10792 & \\
\hline \multirow[t]{3}{*}{ Lowest $20 \%$} & $1.5 \%$ & $20.8 \%$ & $14.8 \%$ & $62.9 \%$ & \multirow[t]{2}{*}{17155} \\
\hline & $19.1 \%$ & $25.9 \%$ & $8.3 \%$ & $20.3 \%$ & \\
\hline & 1363 & 13791 & 30357 & 53219 & 98730 \\
\hline
\end{tabular}

\section{KEY POINTS}

- For each indicator of socioeconomic status (income, occupational position, and qualification), a mortality gradient to the disadvantage of members from the lowest categories was found.

- If mortality risks for income with occupational position and income with qualification were estimated, only meaningful results for income remained.

- The results support the present emphasis on the role of material conditions for variations in health.

- Qualification and occupational position are nevertheless important, as qualification has a placement function for the first occupational position and thus effects on income.

ries (within our statutory health insurance population). If this is extended to the upper $40 \%$ of the income distribution, $52.2 \%$ of insured in the highest positions are covered.

Considering qualification in intersection (table 4) with income gives similar results, but the rank correlation between the two characteristics is low $(r=0.13)$. In the lowest income group the proportion of insured without a formal qualification is $48.3 \%$., Summing up the personnel with 13 years of school and a university degree covers $97 \%$ of the highest income group, but only $11.4 \%$ of the insured with an academic degree fall into the highest income group. These low correlations come about by the small correspondences between the positions in intermediate categories of the variables considered.

In the second step we deal with multivariate relations between social status indicators and mortality with the dependent variable being the age of death or surviving the age of 65 , respectively. The results of the Cox regression are displayed in terms of relative risks. These indicate how much more likely the case of death is for a person of a certain category as compared with the highest category (that is, people with the highest income, the highest occupational position or the highest qualification).

The main research question is related to the contributions of the three indicators under study, predominantly concerning the relative importance of income. In all the analyses to follow gender was introduced as a control variable. This procedure was chosen because a mortality gradient (in terms of relative risks) for all SES indicators emerged likewise for men and women if only one SES indicator was introduced. If only men were considered, the results did not change. However, the confidence intervals for the female study population were large, thus not permitting firm conclusions for women. The reasons are the smaller proportion of women in our population, and the higher life expectancy in women further reduced the number of death cases available.

At first the SES indicators are analysed separately (table 5). Regardless of the indicator 
Table 5 Multivariate Cox regressions: relative mortality risks for income, qualification, occupational position and gender

Model 1: Income in percentiles

\begin{tabular}{|c|c|c|}
\hline & $\begin{array}{l}\text { Relative } \\
\text { risk }\end{array}$ & $\begin{array}{l}95 \% \text { confidence } \\
\text { intervals }\end{array}$ \\
\hline Higher $20 \%$ * & 1.31 & $1.13,1.53$ \\
\hline Mean $20 \%{ }^{\star}$ & 1.78 & $1.52,2.08$ \\
\hline Lower $20 \%$ * & 2.55 & $2.18,2.98$ \\
\hline Lowest $20 \%$ * & 1.77 & $1.48,2.12$ \\
\hline Gender (females) $\dagger$ & 0.28 & $0.25,0.33$ \\
\hline \multicolumn{3}{|l|}{ Model 2: Qualification } \\
\hline & $\begin{array}{l}\text { Relative } \\
\text { risk }\end{array}$ & $\begin{array}{l}95 \% \text { confidence } \\
\text { intervals }\end{array}$ \\
\hline Qualification (1) $\ddagger$ & 2.95 & $1.71,5.09$ \\
\hline Qualification (2) $\ddagger$ & 3.21 & $2.20,4.71$ \\
\hline Qualification (3) $\ddagger$ & 4.21 & $2.87,6.19$ \\
\hline Gender (females) $†$ & 0.46 & $0.41,0.52$ \\
\hline \multicolumn{3}{|c|}{ Model 3: Occupational position } \\
\hline & $\begin{array}{l}\text { Relative } \\
\text { risk }\end{array}$ & $\begin{array}{l}95 \% \text { confidence } \\
\text { intervals }\end{array}$ \\
\hline Skilled non-manual $\S$ & 1.73 & $1.28,2.32$ \\
\hline Skilled manual $\$$ & 3.15 & $2.39,4.16$ \\
\hline Unskilled/semi-skilled $\$ & 3.32 & $2.52,4.36$ \\
\hline Gender (females) $\dagger$ & 0.49 & $0.43,0.55$ \\
\hline
\end{tabular}

$\star$ The highest $20 \%$ of the income distribution serves as reference category. $†$ Men serve as reference category. $¥$ The highest occupational position (intermediates/executives) serves as reference category. $\$$ The highest qualification serves as reference category; Qualification (1): " 13 years of school with or without vocational training"; qualification (2): "nine or 10 years of school and vocational training"; qualification (3): "nine or 10 years or less without vocational training".

Table 6 Multivariate Cox regression: relative mortality risks for income, qualification, and gender

\begin{tabular}{lll}
\hline & Relative risk & $\begin{array}{l}95 \% \text { confidence } \\
\text { intervals }\end{array}$ \\
\hline Higher $20 \%^{\star}$ & 1.30 & $1.11,1.53$ \\
Mean $20 \%^{\star}$ & 1.81 & $1.53,2.13$ \\
Lower $20 \%^{\star}$ & 2.58 & $2.17,3.07$ \\
Lowest $20 \%^{\star}$ & 2.03 & $1.68,2.46$ \\
Qualification (1) $\dagger$ & 1.28 & $0.43,3.81$ \\
Qualification (2) $\dagger$ & 1.29 & $0.54,3.12$ \\
Qualification (3) $\dagger$ & 1.24 & $0.51,2.98$ \\
Gender (females) $\ddagger$ & 0.27 & $0.23,0.31$
\end{tabular}

ॠThe highest $20 \%$ of the income distribution serves as reference category. $†$ The highest qualification group (academic training) serves as reference category. Qualification (1): "13 years of school with or without vocational training"; qualification (2): "nine or 10 years of school and vocational training"; qualification (3): "nine or 10 years or less without vocational training”. $¥$ Men serve as reference category.

Table 7 Multivariate Cox regression: relative mortality risks for income, occupational position and gender

\begin{tabular}{lll}
\hline & $\begin{array}{l}\text { Relative } \\
\text { risk }\end{array}$ & $\begin{array}{l}\text { 95\% confidence } \\
\text { intervals }\end{array}$ \\
\hline Higher $20 \%^{\star}$ & 1.35 & $1.16,1.57$ \\
Mean $20 \%^{\star}$ & 1.83 & $1.57,2.16$ \\
Lower $20 \%^{\star}$ & 2.69 & $2.29,3.17$ \\
Lowest $20 \%^{\star}$ & 1.99 & $1.66,2.39$ \\
Skilled non-manual† & 1.46 & $0.74,2.88$ \\
Skilled manual $\dagger$ & 1.77 & $0.91,3.42$ \\
Unskilled/semi-skilled $\dagger$ & 1.56 & $0.81,3.00$ \\
Gender (females) $\ddagger$ & 0.28 & $0.24,0.32$ \\
\hline
\end{tabular}

$\star$ The highest $20 \%$ of the income distribution serves as reference category. tThe highest occupational position (intermediates/ executives) serves as reference category. $\ddagger$ Men serve as reference category.

considered, compared with the highest income or status category all the remaining ones show increased relative mortality risks. In contrast with qualification and occupational position, the income related mortalities do not show a linear increase with falling income as not the lowest, but the second lowest percentile shows the highest relative risk. In contrast with income, qualification and mortality show an inverse pattern. For occupational position also an inverse relation emerges, but the difference between unskilled/semi-skilled and the skilled manuals is fairly small.

Considering income and qualification (table 6 ), each indicator still yields increased mortality risks. For income, the size of the relative risks persists, but for qualification it decreases, and the confidence intervals widens. A cross tabulation (not shown here) performed separately for deaths and censored cases shows that this is because of small cell frequencies in the subtables displaying the death cases.

If relative risks for income and occupational position are estimated, a similar result emerges (table 7). Again, the relative risks of income remain relatively unchanged while the effects of occupational position decrease, again accompanied by widening confidence intervals.

In the beginning of the methods section we have pointed out that the population eligible for analysis was smaller than the total number of the employed insured. This was because of missing values on at least one SES indicator. To estimate an eventual bias resulting out of this considerable loss of cases, we estimated the mortality risk for people with complete data on all three indicators in comparison with those with at least one missing value. A Cox regression with again controlling for gender yielded a relative risk of $\mathrm{RR}=1.08(95 \% \mathrm{CI}$ : $1.03,1.12)$ - that is, subjects with complete data had a $8 \%$ higher mortality risk.

\section{Discussion}

Our first research question was related to examining empirical overlaps between income, qualification, and occupational position. The starting point was the question whether the shift in the debate on health inequalities is related to a different conceptual content of SES indicators or whether the same is discussed under a different heading.

We used a large data set representing the population of a German statutory health insurance. The associations between qualification and occupational position were strong, the correlations between these two indicators and income were much smaller. A considerable part of unskilled/semi-skilled had a relatively high income level, pointing to the phenomenon of status inconsistency. ${ }^{39} 40$ Two explanations may apply: A substantial part of the insured from lower occupational positions might have been on shift work or they got overtime premiums. Both results in a classification into higher income categories. The second explanation concerns part time employees holding jobs according to their qualification, but their wages are lower than for full timers, and so they fall into lower income categories. Unfortunately, in our data details concerning individual employment conditions were unavailable, the same 
applies for overtime or shift work, thus separate analyses could not be performed.

In the regression analyses for every status indicator a gradient with respect to mortality could be demonstrated, a finding that is already known from the inequality literature. A deviation from the pattern of an inverse relation of mortality risks and SES was income as the lowest $20 \%$ of wage earners show a lower risk than the $20 \%$ above. We assume this (at least partly) to be attributable to part time employment. ${ }^{41}$ In the higher income groups there might have been people from lower ranks of the social scale (in terms of qualification or occupational position) with increased health risks. An earlier study ${ }^{25}$ has likewise demonstrated a non-linear relation between household income and chronic health conditions (page 595). This suggests that a straightforward interpretation of income (or the material situation) may hardly be possible. If material conditions are major determinants for health inequalites, income levels should be associated with differential mortality risks regardless whether subjects are part timers or full time employed. This is again challenged by our lack of information on household budgets or about the amount of money available per person. People may have other sources of income or part timers may be member of a household with more than one wage earner. Both have been found to be important determinants of health inequalities. ${ }^{42}$ It is not unambiguously known whether the income we were dealing with was the only money available, whether an insured was the only person in a household, or whether and how many children were present. ${ }^{43}$

In comparison with qualification and occupational position, income has turned out to be the strongest predictor of mortality. There were still mortality gradients for qualification and occupational position, but the corresponding confidence intervals were large, thus not permitting substantial interpretations. At first this supports a materialistic explanation for health inequalities, but by several reasons, this should not be the last word on this issue. In a recent study, Stronks et $a \bar{l}$ concluded that in addition to effects of material conditions, psychological and behavioural factors may determine mortality risks. Empirically, these were subsumed under the general heading of "confounders", but the related odds ratios were considerable. Another reason for concentrating on income is the temporal order of the three SES indicators. Qualification, especially school education, has a placement function for or it precedes the first occupational position, and it may also determine income opportunities. In a recent publication, Stronks et $a l^{25}$ concluded that the effect of material conditions on health my be attributable to the worse health of unemployed who, after having lost the job, also experience a reduction of incomes. Although this is an interesting conclusion, it does not apply to our data as the income classification is based on wages attributable to employment.

Earlier comparative studies were not concerned with mortality, but with different measures of morbidity, and their results are not con- sistent. Blaxter ${ }^{23}$ reported stronger effects for income than for social class, and $\mathrm{Dahl}^{44}$ found occupational status to be a stronger predictor than income, Winkleby et a ${ }^{4}$ emphasised education, and a study published by Stronks et al ${ }^{25}$ does not permit a clear conclusion.

In contrast with the comparative studies above, our very large data set may lend credibility to the results, but the material is not without problems. The relatively small proportion of women and the lower mortality rate in women did not permit separate analyses for men and women. Thus the results are much more convincing for the male insured while for women the results are not clear. Another problem is the reduced case number because of inconsistencies in the income data. The advantage of having the exact income figures becomes a problem as we often could not compute a yearly income if unusually high or low payments for short periods were recorded. In survey studies, the income information may be less accurate, but the respondents may be able to give the rough amount of a regular income.

The consequences of the large number of income missings for the interpretation of our data are hard to evaluate. It cannot be assessed whether it may result in an overestimation or an underestimation of the social gradients as we do not know the "true" income distribution of our population. One might only conclude that, taking mortality as a criterion, in subjects with income missing values the distribution may be skewed towards the higher income groups as they have a somewhat lower mortality than those with complete income data.

A last problem germane to information from a statutory health insurance may affect the size of the social gradient. The data do not depict the upper $10 \%$ of the population and likewise the subjects from the lowest positions of the social scale, for example, the majority of people on social security or the homeless. Although these groups are comparatively small, omitting them should lead to an underestimation of mortality gradients. To reduce this inaccuracy, for the upper $10 \%$ the inclusion of data from private insurers is a solution while the lowest social groups can hardly be covered appropriately.

Our results emphasise the present discussion on the consequences of material living conditions. Income on the one hand and qualification and occupational position on the other turned out to be largely independent. Mortality related effects of income were more pronounced than those of the other SES indicators. However, seen in a time perspective, qualification has still a placement function at least for the first occupational position.

We thank the AOK Mettmann for giving us the opportunity of using the health insurance data for scientific purposes. We are particularly indebted to Andrea Jung, Irene Jung, Lilli Krüger, and discussions while preparing the material used for this paper.

Funding: none.

Conflicts of interest: none.

1 Mielck A, Rosario Giraldes M. Inequalities in health and health care. Münster: Waxmann, 1993. 
2 Morris J N, Blane DB, White IR. Levels of mortality, education and social conditions in the 107 local education authority areas

3 Kawachi I, Kennedy BP, Kimberly Lochner SM, et al. Social capital, income inequality, and mortality. Am $\mathcal{f}$ Public Health 1997;87:1491-1498

4 Weich S, Lewis G. Material standard of living, social class, and the prevalence of common mental disorders in Great Britain. $\mathscr{f}$ Epidemiol Community Health 1998;52:8-14.

5 Stronks K, van de Mheen HD, Mackenbach JP. A higher prevalence of health problems in low income groups: does it reflect relative deprivation? F Epidemiol Community Health 1998;52:548-57.

6 Ecob R, Davey-Smith G. Income and health: what is the nature of the relationship? Soc Sci Med 1999;48:693-705.

7 Wilkinson RG. Unhealthy societies . London: Routledge, 1996.

8 Wilkinson RG. The impact of income inequality on life expectancy. In: Platt S, Thomas H, Scott S, et al, eds. expectancy. In: Platt S, Thomas $\mathrm{H}$, Scott S, et al, eds. Locating health. Sociological and

9 Kennedy BP, Kawachi I, Prothrow-Stith D. Income distribution and mortality: cross-sectional ecological study of the Robin Hood Index in the United States. BMF 1996; 312:1004-7.

10 Robert SA. Community level socioeconomic status efffects on adult health. F Health Soc Behav 1998;39:18-37.

11 Townsend P, Davidson N, Whitehead M. Inequalities in health. The Black Report and The Health Divide. London Penguin Books, 1992.

12 Power C, Matthews S, Manor O. Inequalities in self rated health in the 1958 birth cohort: lifetime social circumstances or social mobility? BMF 1996;313:449-53.

13 Macintyre S. The Black Report and beyond. What are the issues? Soc Sci Med 1997;44:723-45.

14 Davey Smith G, Hart C, Blane D, et al. Lifetime socioeconomic position and mortality: prospective obser-

15 Watson P. Health difference in Eastern Europe: Preliminary findings from the Nowa Huta Study. Soc Sci Med 1998;46 549-58.

16 Benzeval M, Judge K, Smaje C. Beyond class, race and ethnicity: deprivation and Health in Britain. Health Serv Res 1995;30:163-77.

17 Mackenbach JP. Inequalities in health in The Netherlands according to age, gender, marital status, level of education, degree of urbanisation and region. Eur $\mathcal{f}$ Public Health 1993;3:112-18.

18 Lahelma E. Changes in the social patterning of health? The case of Finland 1986-1994. Soc Sci Med 1997;44:789-99.

19 Liberatos P, Link BG, Kelsey JL. The measurement of social class in epidemiology. Epidemiol Rev 1988;10:87-121.

20 Mackenbach JP, Kunst AE, Cavelaars EJM, et al. Socioeceonomic inequalities in morbidity and mortality in Western Europe. Lancet 1997;349:1655-9.

21 Helmert U, Hermann B, Joeckel KH, et al. Social class and risk factors for coronary heart disease in the Federal Republic of Germany: results of the baseline survey of the Republic of Germany: results of the baseline survey of the
German Cardiovascular Prevention Study. $\mathcal{F}$ Epidemiol Germmunity Health 1989;43:37-42.
22 Link BG, Phelan J. Social conditions as fundamental causes of disease. F Health Soc Behav 1995; extra issue:80-94.

23 Blaxter M. Health and lifestyles. London: Routledge, 1990.

24 Winkleby MA, Jatulis DE, Frank E, et al. Socioeconomic status and health: how education, income and education contribute to risk factors for cardiovascular disease. $\mathrm{Am} \mathcal{F}$ Public Health 1992;82:816-20.

25 Stronks K, Mheen $\mathrm{H}$ van de, Boc J van den. The interrelationship between income, health and employment status. Int F Epidemiol 1997;26:592-600.

26 Kohn M L, Schooler C. Work and personality: An inquiry into the impact of social stratification. Norwood, NJ: Ablex, 1983.

27 Hoff E-H. Arbeit, Freizeit und Persönlichkeit /Work, leisure time, and personality]. Heidelberg: Asanger, 1992.

28 Karasek R, Theorell T. Healthy work. New York: Basic Books, 1990.

29 Johnson J V, Stewart W, Hall EM, et al. Long-term psychosocial work environment and cardiovascular mortality among Swedish men. Am f Public Health 1996;86:324-31.

30 Siegrist J. Soziale Krisen und Gesundheit [Social crises and health]. Göttingen: Hogrefe and Huber, 1996.

31 Statistisches Bundesamt. Statistisches fahrbuch 1989 [Statistical Yearbook 1998]. Stuttgart: Metzler and Poeschel, 1989.

32 Statistisches Bundesamt. Statistisches fahrbuch 1997 [Statistical Yearbook 1997]. Stuttgart: Metzler and Poeschel, 1997.

33 Bundesanstalt für Arbeit. Schlüsselverzeichnis für die Angaben zur Tätigkeit in den Versicherungsnachweisen [Code manual for occupational information in insurance certificates]. Nürnberg: Bundesanstalt für Arbeit, 1992.

34 Parmentier IK, Schade H-J, Schreyer F. Berufe im Spiegel der Statistik [Statistics of the distribution of occupations] 19851995. Nürnberg: Institut für Arbeitsmarkt-und Berufsforschung, 1996.

35 Cox D R, Oakes D. Analysis of survival data. London: Chapman and Hall, 1984

36 Collett D Modelling survival data in medical research. London: Chapman and Hall, 1994.

37 Norusis M J, SPSS Inc. SPSS for Windows manual, advanced statistics for version 6. Chicago: SPSS Inc, 1993.

38 Stata Corp. Stata statistical software: Release 6.0. College Station, TX: Stata Corporation, 1999.

39 Hradil S Soziale Ungleichheit in Deutschland [Social inequality in Germany]. Opladen: Leske and Budrich, 1999.

40 Muntaner C, Stormes J. Social class and behavior: simultaneuous class positions yield different amounts of income. Psychol Rep 1996;79:379-82.

41 Arber S. Comparing inequalities in women's and men's health: Britain in the 1990s. Soc Sci Med 1997;44:773-87.

42 Kaplan GA, Pamuk E, Lynch J, et al. Inequality in income and mortality in the United States: analyses of mortality and potential pathways. BMF 1996;312:999-1003.

43 Townsend P. The international analysis of poverty. New York: Harvester Wheatsheaf, 1993.

44 Dahl E. Social inequalities in ill-health: the significance of occupational status, education and income-results from a Norwegian survey. Sociol Health Illness 1994;16:644-67. 